\title{
Characterization of an Effective CTL Response against HIV and SIV Infections
}

\author{
Meritxell Genescà \\ Health Sciences Research Institute, Germans Trias i Pujol, 08916 Badalona, Spain \\ Correspondence should be addressed to Meritxell Genescà, mgenesca@igtp.cat
}

Received 1 July 2011; Accepted 1 August 2011

Academic Editor: Zhengguo Xiao

Copyright () 2011 Meritxell Genescà. This is an open access article distributed under the Creative Commons Attribution License, which permits unrestricted use, distribution, and reproduction in any medium, provided the original work is properly cited.

A vaccine inducing protective immunity in mucosal tissues and secretions may stop or limit HIV infection. Although cytotoxic T lymphocytes (CTLs) are clearly associated with control of viral replication in HIV and simian immunodeficiency virus (SIV) infections, there are examples of uncontrolled viral replication in the face of strong $\mathrm{CD} 8^{+} \mathrm{T}$-cell responses. The number of functions, breadth, avidity, and magnitude of CTL response are likely to be important factors in the effectiveness of anti-HIV T-cell response, but the location and persistence of effector $\mathrm{CD} 8^{+} \mathrm{T}$ cells are also critical factors. Although the only HIV vaccine clinical trial targeting cellular immunity to prevent HIV infection failed, vaccine strategies using persistent agents against pathogenic mucosal challenge in macaque models are showing unique success. Thus, the key to control the initial focus of viral replication at the portal of entry may rely on the continuous generation of effector CTL responses at mucosal level.

\section{Introduction}

Cytotoxic T lymphocytes (CTLs) play a significant role controlling viral replication in HIV and simian immunodeficiency virus (SIV) infections as exemplified by diverse facts such as the association of Gag-specific CTL activity and viremia or progression to AIDS [1, 2], the viral escape consequence of immune selection $[3,4]$ or by enhanced CTL function in elite controllers (EC) [5-8]. In macaque models, this association has been reinforced by depletion studies [911] or by studying the mechanisms of protection in live, attenuated SIV vaccine models $[12,13]$.

Yet, not all AIDS vaccines that have shown induction of strong specific T-cell responses are protective or assure effective control of HIV/SIV [14, 15]. Factors, both intrinsic and extrinsic to CTLs, may be critical for determining the ability of $\mathrm{CD} 8^{+} \mathrm{T}$ cells to effectively control HIV/SIV replication. Several intrinsic parameters-inherent to the CTL response- - have been shown to correlate with control of viremia and/or disease progression (TCR repertoire and public clonotypes, avidity, polyfunctionality, killing capacity, etc.) $[16-18]$.

Extrinsic factors affecting the CTL response such as the inflammatory and regulatory environment also determine the quality and persistence of $\mathrm{CD} 8^{+} \mathrm{T}$ cells. These external factors affect the ratio between target cells and effector cells [19] or influence the phenotype and functionality of $\mathrm{CD} 8^{+}$ effector cells $[17,20]$, all contributing to viral control. From animal model studies, we are learning that the generation and maintenance of a CTL response that is located at the mucosal site of viral transmission is beneficial against mucosal challenge with pathogenic SIVmac $[12,21]$.

\section{Qualitative Aspects of the CTL Response}

$\mathrm{CD}^{+} \mathrm{T}$ lymphocytes interact with virus-infected cells by recognizing viral peptides presented on the cell surface by major histocompatibility complex class I molecules. Once this cognate interaction occurs, there is induction of numerous genes involved in cell cycle, proliferation, apoptosis, and cytokine secretion. If this interaction induces killing of the virus-infected target cell, this can occur through two main pathways $[7,22]$. CTLs can bind to receptors of the tumor necrosis factor superfamily (e.g., Fas-mediated killing) on the surface of the target cells or deliver the contents of cytotoxic granules to these target cells, both cases ultimately inducing cell death. Not only is the granule-independent 
pathway involving Fas/FasL interaction a less frequent mode of target cell killing, but also during HIV and SIV infections this pathway is highly activated and contributes to reduced cellular immunity and disease progression by activationinduced cell death of bystander cells [23]. The second pathway is mediated by perforin, which promotes granzyme delivery to the target cell cytosol, substrate cleavage, and cell death induction. Lately several papers have reported enhanced cytotoxic function in HIV-specific $\mathrm{CD}^{+} \mathrm{T}$ cells from EC $[7,22]$, including a superior ability to express perforin and granzyme B, with no detectable difference in the levels of granzyme A or granulysin, and the transcription factor $\mathrm{T}$ bet is the enhancer of this effector activity [7]. Degranulating capacity at mucosal level, measured by CD107 expression, has also been associated with protection against vaginal challenge with SIV [24], where at early timepoints after challenge there was significantly less degranulation capacity in the vaginal $\mathrm{CD} 8^{+} \mathrm{T}$ cells of control animals than in the immunized macaques. Moreover, $\mathrm{CD}^{+} \mathrm{T}$ cells from mucosal tissues may be more efficient at suppressing viral replication ex vivo than cells from blood [13]. Interestingly, compared to prime-boost regimens, vaccination with live, attenuated SIV resulted in a faster kinetics of cytolysis by SIV-specific CTLs, with rapid and robust degranulation and granzyme $\mathrm{B}$ release from tetramer-positive $\mathrm{CD} 8^{+} \mathrm{T}$ cells [25]. All these findings suggest that mucosal CTL mechanisms are contributing to the success of live, attenuated vaccines. Yet, we need to determine if all the specific molecules involved in these cytotoxic mechanisms are expressed at sufficient levels in the genital mucosa. This is important because CTLs from the gastrointestinal (GI) mucosa express low perforin [26], and measurement of CD107 could be overestimating CTL function if lacking other components. CD107 is expressed on the CTL surface when the lytic granules are discharged during target-cell lysis, thus CD107 staining quantifies the recent killing history of CTLs. But the ability of $\mathrm{CD}^{+} \mathrm{T}$ cells to induce target cell death is dependent on granule protein content rather than on the act of degranulation itself [27]. Still previous studies have shown that the presence of $\mathrm{CD} 107^{+} \mathrm{T}$ cells correlated well with cytotoxic activity [28] and, although CTLs from the GI tract contain low perforin, an increase in the levels of perforin in gut accompanies the appearance of the SIV-specific $\mathrm{CD}^{+}{ }^{+} \mathrm{T}$-cell response during acute SIV infection [26].

The qualitative aspects of the T-cell response and specifically the capacity of revealing multiple functions upon antigen stimulation is currently seen as one of the best correlates of T-cell immunity measurable directly ex vivo [16], since preservation of polyfunctional HIV-specific CD8 ${ }^{+}$ $\mathrm{T}$ cells is associated with control of viremia in infected people [29] and with protection from uncontrolled viral replication in vaccinated rhesus monkeys after SIV infection [30]. Polyfunctional $\mathrm{CD}^{+} \mathrm{T}$ cells degranulate and produce multiple functional molecules, such as interleukin-2, interferon- $\gamma$, and tumor necrosis factor. Importantly, this correlation is also reported in mucosal tissues, where polyfunctional Gagspecific $\mathrm{CD}^{+} \mathrm{T}$ cells are significantly more abundant in rectal mucosa from controllers as compared to noncontrollers and patients under antiretroviral therapy [6] or in the genital tract of the immunized macaques in live, attenuated vaccine models [24]. Further, the most polyfunctional cells produce higher levels of cytokine on a per-cell basis [17]. Yet, there is no consensus on which cytokines and molecules are critical to control viral replication and, thus, should be measured by these polychromatic flow cytometry assays [31].

All these features are related to the specific ligandreceptor recognition, among other intrinsic parameters, which are ultimately limited by the T-cell receptor (TCR) expressed by a particular CTL clone. Studies in this area have recognized the importance of the TCR repertoire mobilized against infection and the beneficial effect on vaccine efficacy of the public composition against viral conserved regions of these recruited clonotypes [32]. The repertoire engaged will impact on the breadth of the CTL response (number of epitopes targeted) and the balance between immunodominant and subdominant responses, both affecting viral load [33]. Interestingly, significant overlap in the clonality and immunodominance hierarchy of the $\mathrm{CD} 8^{+} \mathrm{T}$ cells isolated from blood and GI mucosa has been demonstrated [26].

Possibly even more crucial, and independent of the specific clonotype [34] may be the intensity of the TCRmediated signal, which is directly linked to $\mathrm{CD}^{+}$T-cell polyfunctionality and HIV-suppressive activity [16]. CD8 ${ }^{+} \mathrm{T}$ cells with high avidity can recognize low densities of cognate antigen on the target cell surface, resulting in effective target cell clearance; which may correspond to a superior capacity to suppress HIV replication [16]. The importance of these high-avidity CTLs on viral dissemination and infection clearance in animal models, especially of those induced at mucosal level, has also been established [35]. Further, two recent studies associate the effectiveness of a CTL response and their high avidity with a narrow, public clonotypic repertoire $[18,36]$. While recruiting high-avidity clones may be desirable to promote vaccine efficacy, viral escape is not impaired [18]. Yet, limiting initial virus replication at the mucosal level may impair the capacity of escape mutants to emerge stochastically.

\section{Phenotype of the CTL Response}

There is doubt on the importance of the phenotype of the $\mathrm{CD}^{+} \mathrm{T}$-cell response in relation to the protective efficacy in vivo, and little difference in the functional capacity when comparing cells across a wide range of phenotypes has been shown [17, 31]. Still, several aspects related to extrinsic factors surrounding the specific response influence antigen sensitivity and the functional profile [16]. This way, viral load and immune activation may induce transient hyporesponsiveness or cell exhaustion, ultimately generating less functional CTLs. In fact, antigen load and viral sequence diversification determine the functional profile of HIV-1specific $\mathrm{CD}^{+} \mathrm{T}$ cells $[20]$.

Exhausted $\mathrm{T}$ cells express increased amounts of multiple inhibitory receptors, such as programmed death-1 (PD1) among others $[37,38]$. PD-1 regulates T-cell activation and tolerance through mechanisms such as anergy and development of induced regulatory $\mathrm{T}$ cells. The implication 
of PD-1 on the functional capacity of the $\mathrm{CD} 8^{+} \mathrm{T}$-cell response in chronic viral infections has been widely reported [37] and sustained antigen-specific TCR stimulation may be key to persistent expression of this regulatory molecule [20]. A recent paper demonstrates that PD-1 can cause Tcell exhaustion by upregulating a gene that inhibits T-cell function [39], where enforced expression of basic leucine transcription factor ATF-like (BATF) was sufficient to impair T-cell proliferation and cytokine secretion. Furthermore, $\mathrm{CD}^{+} \mathrm{T}$ cells in lymph nodes and Gl mucosa of infected macaques express high levels of PD-1 while significant reduction in plasma viral load and improved functionality of these SIV-specific $\mathrm{CD} 8^{+} \mathrm{T}$ cells was reached by blocking PD-1 [40].

Expression of the killer cell lectin-like receptor G1 (KLRG1) on $\mathrm{T}$ cells has recently been shown to have a functional role on human $\mathrm{CD}^{+} \mathrm{T}$ cells inhibiting the proliferative capacity of highly differentiated $\mathrm{CD} 8^{+} \mathrm{T}$ cells [41]. Similarly, CD57 is a human natural killer-1 (HNK-1) glycoprotein found on many NK cells and a subset of $\mathrm{CD}^{+}$ $\mathrm{T}$ cells, where it has been reported to identify terminally differentiated $\mathrm{T}$ cells with reduced proliferative capacity [42]. Both these markers have been suggested to identify replicative senescent cells, but the functional capacity and the correlation of cells expressing these markers with viral load in the context of HIV/SIV is unknown. It has been shown that due to chronic T-cell activation HIV-specific $\mathrm{CD}^{+}$ $\mathrm{T}$ cells may become replicative senescent, express CD57, and become prone to activation-induced apoptosis [43]. This may be reflective of normal T-cell development during chronic stimulation and thus not necessarily a defect within the HIV-specific $\mathrm{CD} 8^{+} \mathrm{T}$ cells, since they maintain effective cytotoxic potential $[44,45]$. Moreover, the damage to gut epithelium may trigger ligation of the inhibitory receptor KLRG-1 by E-cadherin [46], which inhibits the effector functions of KLRG1 1 hi-expressing HIV-1-specific $\mathrm{CD}^{+} \mathrm{T}$ cells systemically.

It has also been shown that the majority of HIV-specific $\mathrm{CD}^{+} \mathrm{T}$ cells are found to express CD57, with or without $\mathrm{PD}-1$, and that $\mathrm{CD} 57^{+} \mathrm{PD}-1^{-}$have higher survival potential (more resistant to apoptosis) than $\mathrm{CD} 57^{+} \mathrm{PD}-1^{+}$. In fact, $\mathrm{PD}-1$ has been shown to be a preapoptotic factor for $\mathrm{CD} 8^{+} \mathrm{T}$ cells in HIV infection [47, 48]. In a live, attenuated SIV vaccine experiment the increased survival potential of the Gagspecific $\mathrm{CD}^{+} \mathrm{T}$ cells was associated to control of viremia at set-point [30], a feature observed in these macaques during acute infection and restricted to the genital tissue [24]. The induction of protective prosurvival molecules (members of the Bcl-2 family) occurs initially through TCR-mediated specific activation of $\mathrm{T}$ cells, but, as differentiation proceeds, this is followed by a decline in Bcl-2 expression and an increase in cell death signals (i.e., caspases) [49]. However, the strength of the stimulation determines the level and duration of Bcl-2 expression [50]. Defining the expression of these molecules in antiviral $\mathrm{T}$ cells may be critical for understanding the nature of the protective $\mathrm{T}$-cell response.

Although a phenotypic definition of a protective antiSIV/HIV T-cell response is still lacking [31], specific phenotypes have been associated with certain functional attributes
[17]. In this sense, HIV-specific $\mathrm{CD}^{+} \mathrm{T}$ cells in HIV controllers have a unique HLA-DR ${ }^{+} \mathrm{CD}^{-} 8^{-}$phenotype and the cells of these patients effectively suppress HIV-1 infection in vitro [8]. Further, development of $\mathrm{HLA}_{-}-\mathrm{DR}^{+} \mathrm{CD} 38^{-} \mathrm{CD} 8^{+}$ $T$ cells during HIV infection was associated with subsequent stable $\mathrm{CD} 4^{+} \mathrm{T}$-cell levels and good prognosis [51]. CD8 ${ }^{+} \mathrm{T}$ cells from normal uninfected humans express little CD38 or HLA-DR; however, during HIV seroconversion there is an increase in the subset of cells expressing both markers, and this activated population probably includes the CTL that develop during acute HIV infection [52]. The frequency of $\mathrm{T}$ cells expressing CD38 in uninfected rhesus macaques is higher than in humans and the frequency of HLA-DR ${ }^{+} \mathrm{T}$ cells is lower in macaques compared to humans. However, once infected the dynamics of expression on $\mathrm{T}$ cell in humans and macaques and the prognostic value of both these markers are similar [53]. Interestingly, degranulating SIV-specific $\mathrm{CD}^{+} \mathrm{T}$ cells $\left(\mathrm{CD} 107^{+}\right)$have more HLA-DR expression than the total $\mathrm{CD}^{+}$T-cell population in SIV infected macaques (unpublished data). These findings are consistent with the hypothesis that HLA-DR expression on anti-SIV CD8 ${ }^{+} \mathrm{T}$ cells indicates cells with enhanced cytolytic capacity, as proposed in EC [8]. Similarly, a human vaccine experiment identified $\mathrm{CD}_{3} 8^{+}, \mathrm{HLA}-\mathrm{DR}^{+}, \mathrm{Ki}-67^{+}$, and $\mathrm{Bcl}-2$ low in $\mathrm{CD}^{+} \mathrm{T}$ cells as effector $\mathrm{T}$-cell responses after immunization or infection [54]. By monitoring the expression of these markers in the blood, they confirmed the increasing population of effector $\mathrm{CD}^{+} \mathrm{T}$ cells, which correlated with tetramer and interferon gamma secreting specific $\mathrm{CD} 8^{+} \mathrm{T}$ cells after immunization with live, attenuated yellow fever$17 \mathrm{D}$ vaccine [54].

\section{Effects of Antigen Persistence and Location}

HIV is transmitted primarily by sexual contact, and the female genital tract, male genital tract, and rectum are the anatomic sites of virus transmission [55]. Recent studies have conclusively demonstrated that immediately after mucosal transmission most systemic HIV and SIV infections are established by a very limited number of viral envelope variants [56]. Before virus dissemination occurs, few days after infection [57], it may be possible to contain and eliminate these initial founder viral populations at the site by vaccineinduced effector $\mathrm{T}$ cells. Importantly, localized mucosal memory T-cell populations provide superior control of viral infection compared with circulating memory $\mathrm{T}$ cells. Yet, since intravaginal or rectal immunization is not a viable option, we have to think of other ways to establish this memory mucosal response.

Central memory (CM) T lymphocytes have limited effector function, but they have the capacity to home and reside in lymphoid organs and, upon secondary exposure to their cognate antigen, they rapidly proliferate to become effector $\mathrm{T}$ cells [58]. In contrast, effector memory (EM) T lymphocytes home to peripheral tissues and, following antigenic stimulation, have limited proliferative capacity but have the ability to degranulate and rapidly produce effector cytokines $[27,58]$. It is reasonable to think that EM-specific $\mathrm{CD}^{+}$ 
$\mathrm{T}$ cells will be more effective at eliminating virus-infected cells while generating less proinflammatory cytokines, thus attenuating activation and inflammatory events. In fact, a successful model of live, attenuated vaccine increases the total number of circulating $\mathrm{CD} 8^{+} \mathrm{T}$ cells [24] and, specifically, the EM CD8 ${ }^{+} \mathrm{T}$-cell phenotype (unpublished observations) while it blunts proliferation, activation, and apoptotic cell death [12]. Simultaneously, polyfunctional $\mathrm{CD}^{+} \mathrm{T}$ cells with high cytotoxic capacity are present in the vagina of these immunized animals on the day of SIV challenge and these effector T cells mediate protection in this model [24]. Other successful live, attenuated vaccines elicit mucosal CTL responses that are more effective at suppressing viral replication than $\mathrm{CD}^{+} \mathrm{T}$ cells from blood [13]. Similarly to these models, an immunization strategy using a replication competent cytomegalovirus (CMV) vector expressing multiple SIV antigens establishes persistent SIV-specific EM Tcell responses at potential sites of SIV replication conferring protection from mucosal challenge in $50 \%$ of the immunized animals [21,59].

The success of these CMV-vector SIV vaccines and of live, attenuated vaccines indicates that, so far, only replicating vaccine virus that disseminates throughout the body and produces antigen continuously, albeit at a low level, in the mucosal tissues may be capable of providing protective immunity $[12,13,21]$. While many of the other systemically administered vaccine strategies may decrease viral replication after immunized animals become infected, none can block infection (reviewed in [60]). Several features of these persistent vaccines that differ from other vaccine strategies could explain the effectiveness of $\mathrm{CD}^{+} \mathrm{T}$-cell responses in these models $[12,13,21]$. Out of these, chronic low-level of antigenic stimulation from residual vaccine replication in tissues, including the mucosa affected, up to the time of challenge and the consequent generation and maintenance of a resident effective antiviral immune response at the portal of virus entry may be the key points to understand protection (Figure 1). This effective antiviral immune response is characterized by $\mathrm{EM} \mathrm{CD} 8^{+} \mathrm{T}$ cells, which will help maintain a more homeostatic environment [27, 58]. Then, it is not surprising that these replicating vaccines, in contrast to other more conventional vaccine strategies (Figure 1(a)) occurred without anamnestic T-cell responses $[12,21]$. The concept that a persistent, attenuated viral vaccine that maintains a pool of $\mathrm{CD} 8^{+}$effector $\mathrm{T}$ cells capable of controlling but not eliminating the pathogen is necessary for protection against persisting pathogens like HIV or SIV was first proposed by Zinkernagel [61]. Similarly, in models of tuberculosis, promising mucosal vaccine systems that use antigen persistence to generate protective $\mathrm{CD} 8^{+} \mathrm{T}$ cells maintained independently of peripheral supply have been described [62].

Although the CMV vector vaccine increased resistance to rectal SIV challenge, virus replication in immunized animals that became infected was not altered [59]. The immunologic basis for the all or none protection phenomena seen in this study remains to be defined but the results are similar to the all or none protection seen in both recently completed human AIDS vaccine efficacy trials [63-65]. In contrast, live, attenuated vaccines induce control of viremia when the infection is productive $[66,67]$. This difference could be related to some of the requirements of live, attenuated vaccines to be protective, like the necessity of vigorous viral replication for the generation of an effective anti-SIV immune response [68].

\section{Target Cell Number and the CTL Response}

As proposed by Zinkernagel, "protection by immunity represents an equilibrium between optimal resistance against the various cytopathic infections and avoidance of excessive immunologically mediated tissue damage" [61]. This is particularly crucial in HIV/SIV infection, since the initial viral insult initiates an inflammatory cascade and immune activation that, if not resolved soon enough, will contribute to virus dissemination and infection amplification (reviewed in [69]). In the case of the natural host, immune activation appears to be detrimental for control of viral replication and disease progression [70] while EC maintain high levels of HIV-specific immune responses with low levels of immune activation [71].

In this sense, a live, attenuated vaccine model has shown that the relative number of SIV target cells compared to the number of SIV vaccine-induced antiviral $\mathrm{T}$ cells in the vagina determines the outcome of vaginal SIV challenge in immunized animals, since $\mathrm{CD} 8^{+} \mathrm{T}$ cell-depleted, vaccinated animals had the highest levels of SIV replication in the genital tract and genital lymph nodes [22, 67]. In fact, the viral RNA levels in these tissues exceeded those found in the GI tract of control animals [72]. This very high level of viral replication in the vagina and genital lymph nodes is unprecedented and suggests that in the absence of antiviral $\mathrm{CD}^{+} \mathrm{T}$ cells, SIV replication in the genital tract was enhanced by prior SHIV immunization. Since SHIV-immunized animals have numerous SIV-specific $\mathrm{CD}^{+} \mathrm{T}$ cells in the vaginal mucosa on the day of challenge [73], it seems likely that they provide more cellular targets compared to the naïve animals, which leads to enhanced local viral replication. This result demonstrates that viral replication after challenge results from a balance between SIV replication in abundant target cells and efficient killing of those infected target cells by antiviral $\mathrm{CD} 8^{+} \mathrm{T}$ cells. In this sense, recent studies highlight the importance of the number of effector CTLs in relation to the number of target cells ( $\mathrm{E}: \mathrm{T}$ ratios) to significantly reduce viral load in the female reproductive tract [19]. Of note, the induction of effector-memory-like $\mathrm{CD} 4^{+} \mathrm{T}$ cells in mucosal tissues might contribute to the protection in live, attenuated SIV vaccine models [73] and in HIV controllers [74]. Although the role of $\mathrm{CD} 4^{+} \mathrm{T}$ cells in viral infection is commonly attributed to helper functions generating and supporting memory $\mathrm{CD}^{+} \mathrm{T}$ cell-responses [75], antiviral cytokine production, and lytic functions have been described in herpes simplex virus type 1, Friend leukemia virus, and HIV infection for $\mathrm{HIV}$-specific $\mathrm{CD}^{+} \mathrm{T}$ cells [73].

Thus, the same mediators that initiate immune activation leading to antiviral immune responses also activate and 


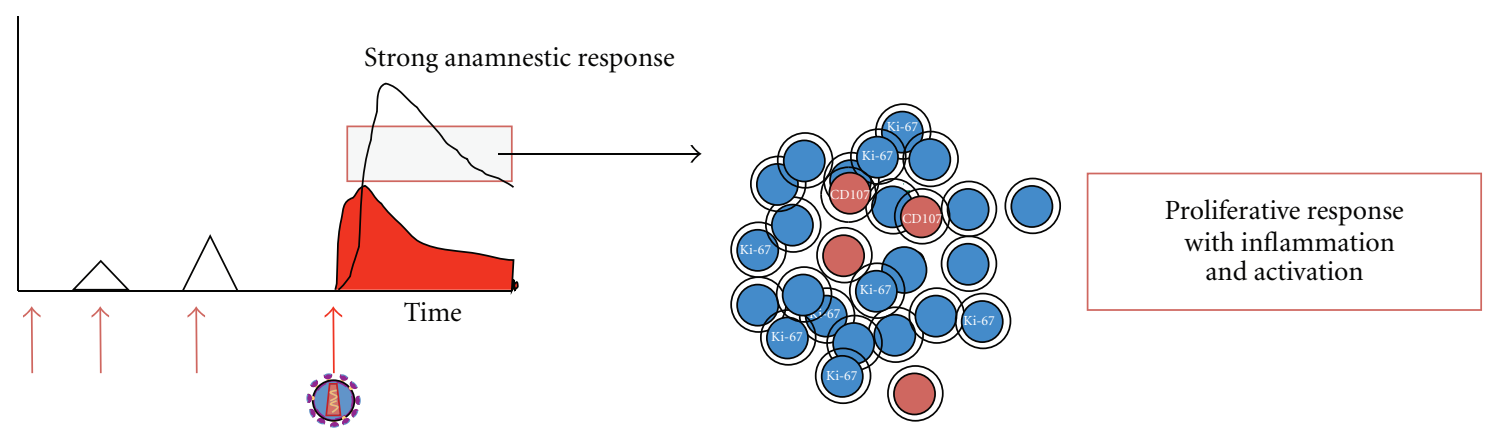

(a) DNA prime viral vector boost
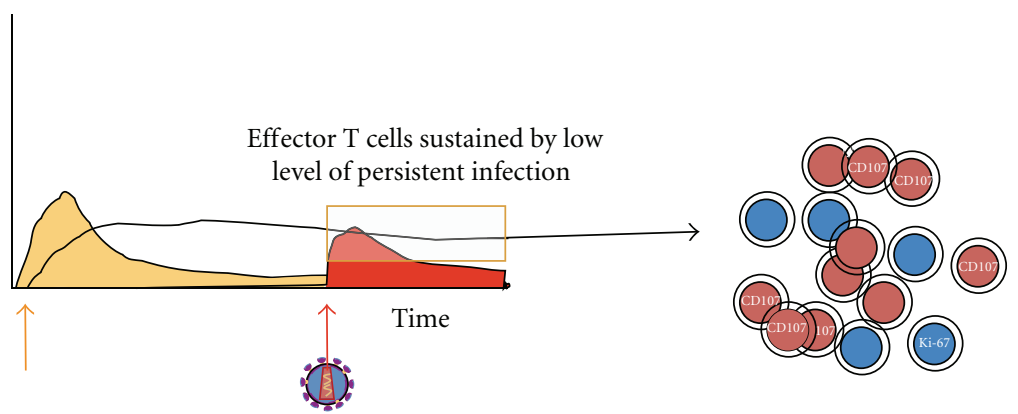

Continuous production of

local effector $\mathrm{CD}^{+} \mathrm{T}$ cells with minimal proliferation

(b) Live, attenuated vaccine

FIgure 1: Hypothetical model for distinct CTL response depending on the immunization strategy. (a) and (b) graphs depict both CTL response and viremia ( $y$-axes) over time ( $x$-axes). Time ( $x$-axes) includes the period of immunization and the period of infection after pathogenic challenge (bright red arrow with virus illustration). A DNA prime viral vector boost strategy (a) induces blips of CTL response after each immunization (with an associated memory response). Upon pathogenic challenge, this strategy generates a strong anamnestic response that has greater memory than effector $\mathrm{CD} 8^{+} \mathrm{T}$-cell component, which will enhance the proliferative response and the associated inflammation and immune activation. In contrast, a live, attenuated vaccine (b) generates persistent CTL response coupled to vaccine virus replication. The continuous production of effector $\mathrm{CD}^{+} \mathrm{T}$ cells is sustained by low level of persistent infection in different tissues, including the mucosa. At the time of virus challenge, the presence of local effector CTLs is capable of controlling the initial focus of viral replication with minimal proliferation, since these cells have more cytotoxic than proliferative potential.

recruit $\mathrm{CD} 4^{+} \mathrm{T}$ cells to tissues that serve as the primary target cells for viral infection. Cytokines and chemokines regulate cell migration and activation, and these molecules will also determine antiviral T-cell fate $[76,77]$. Moreover, the inflammatory milieu is a critical factor controlling the differentiation of primary antiviral $\mathrm{CD}^{+} \mathrm{T}$ cells into terminally effector cells or long-lived memory T cells. Prolonged inflammation or stimulation by the T-cell transcription factor, T-bet, results in a predominantly short-lived, effector $\mathrm{CD} 8^{+} \mathrm{T}$-cell population rather than a long-lived memory population with proliferative potential [78]. Thus, the $\mathrm{CD}^{+} \mathrm{T}$-cell response that is observed in the SHIV-vaccinated monkeys that are protected from pathogenic SIVmac challenge is consistent with an effector T-cell population driven by continuous antigen production rather than a large memory T-cell pool associated with anamnestic proliferation (Figure 1(b)). Yet, the presence of central-memory $\mathrm{T}$ cells in the draining lymph node and a balance between these cells and effector $\mathrm{CD} 8^{+} \mathrm{T}$ cells in the mucosa may be required to maintain an effective anti-SIV T cell response [24].

Finally, another way to control the number of target cells and avoid excessive immune activation and inflammation could be through the induction of regulatory T cells $[79,80]$. However, the role of these regulatory $\mathrm{T}$ cells remains controversial, since they could both reduce immune activation and limit development of specific adaptive responses. In this sense, elevated frequencies of regulatory cells associated to low levels of immune activation may contribute to the ability of some individuals to avoid HIV infection [81]. Further, after SIV challenge, a quiescent tissue environment is actively maintained by a T-regulatory cell response that rapidly expands to suppress immune activation preventing the generation of more activated target cells to support SIV replication ([60]; manuscript in preparation). Active 
immunoregulatory mechanisms, rather than intrinsically attenuated innate immune responses, efficiently downregulate the robust innate immune responses that also occurs soon after SIV infection of the natural host, the African green monkey, in which persistent SIV infection is relatively nonpathogenic [79]. Thus, it seems that the persistent, low-level replication of SHIV infection modulates the immunological response to pathogenic SIV challenge such that the response resembles that of natural host nonhuman primates, where low levels of T-cell activation, proliferation, and apoptosis are also observed after SIV infection [82-84].

\section{Concluding Remarks}

From a vaccine development viewpoint, defining the specific subset of $\mathrm{CD} 8^{+} \mathrm{T}$ cells that are responsible for control of viral replication could inform HIV vaccine design and the search for an immune correlate of protection. There is compelling evidence from live, attenuated SIV vaccine models and from the recent CMV-vector vaccine experiments that the critical $\mathrm{T}$ cell is an effector $\mathrm{CD}^{+} \mathrm{T}$ cell that does not undergo anamnestic proliferation as detected in the blood. Yet, the challenge exists on evaluating these responses at mucosal level, where the picture seems to be completely different than the snapshot we can get from peripheral blood. Although studying mucosal immunity is technically challenging due to difficulty in obtaining samples of sufficient quality and quantity for analysis, the need to improve the relatively low efficacy of the systemic AIDS vaccines currently in development demands a focus on eliciting mucosal immune responses through vaccination. Further, a careful design of standardized protocols for collecting and analyzing mucosal specimens in preclinical and clinical trials is critical for assessing immunogenicity in HIV vaccine candidates.

Although conventional vaccines attempt to elicit strong anamnestic $\mathrm{CD}^{+}{ }^{+} \mathrm{T}$-cell responses after HIV exposure, caution may be needed in that pursuit. Lessons learnt from successful persistent vaccines indicate that protection against mucosal HIV transmission requires induction of resident mucosa effector $\mathrm{CD}^{+} \mathrm{T}$ cells but little systemic T-cell proliferation $[12,13,21]$. A complex immune environment allows memory effector $\mathrm{CD}^{+} \mathrm{T}$ cells in the vagina on the day of challenge to effectively kill infected cells by not providing additional substrate for virus replication [60] whilst unique control against rectal challenge is conferred by high-frequency SIV-specific $\mathrm{T}$ cells induced through persistent CMV vectors $[12,21]$. Both systems maintain a resident effector response indefinitely that can protect without anamnestic expansion [12, 21]. Development of alternative strategies to replicating vaccines to induce mucosa immunity in the reproductive tract using adjuvants is warranted [85]. Other routes of virus transmission like blood transfusions and mother-to-child may require different vaccination strategies. Considering the outcome of recent clinical trials, refined animal models may help to define the type of complex immunological response an HIV/SIV vaccine candidate may need to elicit to be effective.

\section{Acknowledgments}

The author thanks Dr. McChesney for thoughtful review of the paper. The author is supported by the Ramón y Cajal program of MICINN (Spain).

\section{References}

[1] P. Kiepiela, K. Ngumbela, C. Thobakgale et al., "CD8 ${ }^{+}$Tcell responses to different HIV proteins have discordant associations with viral load," Nature Medicine, vol. 13, no. 1, pp. 46-53, 2007.

[2] Y. Riviere, M. B. McChesney, F. Porrot et al., "Gag-specific cytotoxic responses to HIV type 1 are associated with a decreased risk of progression to AIDS-related complex or AIDS," AIDS Research and Human Retroviruses, vol. 11, no. 8, pp. 903-907, 1995.

[3] P. J. R. Goulder, C. Brander, Y. Tang et al., "Evolution and transmission of stable CTL escape mutations in HIV infection," Nature, vol. 412, no. 6844, pp. 334-338, 2001.

[4] T. M. Allen, D. H. O'Connor, P. Jing et al., "Tat-specific cytotoxic T lymphocytes select for SIV escape variants during resolution of primary vimamia," Nature, vol. 407, no. 6802, pp. 386-390, 2000.

[5] B. L. Shacklett and A. L. Ferre, "Mucosal immunity in HIV controllers: the right place at the right time," Current Opinion in HIV and AIDS, vol. 6, no. 3, pp. 202-207, 2011.

[6] A. L. Ferre, P. W. Hunt, J. W. Critchfield et al., "Mucosal immune responses to HIV-1 in elite controllers: a potential correlate of immune control," Blood, vol. 113, no. 17, pp. 3978-3989, 2009.

[7] A. R. Hersperger, J. N. Martin, L. Y. Shin et al., "Increased HIV-specific $\mathrm{CD}^{+}$T-cell cytotoxic potential in HIV elite controllers is associated with T-bet expression," Blood, vol. 117, no. 14, pp. 3799-3808, 2011.

[8] A. Sáez-Cirión, C. Lacabaratz, O. Lambotte et al., "HIV controllers exhibit potent CD8 $\mathrm{T}$ cell capacity to suppress HIV infection ex vivo and peculiar cytotoxic T lymphocyte activation phenotype," Proceedings of the National Academy of Sciences of the United States of America, vol. 104, no. 16, pp. 6776-6781, 2007.

[9] J. E. Schmitz, M. J. Kuroda, S. Santra et al., "Control of viremia in simian immunodeficiency virus infection by $\mathrm{CD}^{+}$ lymphocytes," Science, vol. 283, no. 5403, pp. 857-860, 1999.

[10] X. Jin, D. E. Bauer, S. E. Tuttleton et al., "Dramatic rise in plasma viremia after $\mathrm{CD}^{+} \mathrm{T}$ cell depletion in simian immunodeficiency virus-infected macaques," Journal of Experimental Medicine, vol. 189, no. 6, pp. 991-998, 1999.

[11] T. Gaufin, R. M. Ribeiro, R. Gautam et al., "Experimental depletion of $\mathrm{CD}^{+}$cells in acutely SIVagm-Infected African Green Monkeys results in increased viral replication," Retrovirology, vol. 7, article 42, 2010.

[12] M. Genescà, M. B. McChesney, and C. J. Miller, "Antiviral $\mathrm{CD}^{+} \mathrm{T}$ cells in the genital tract control viral replication and delay progression to AIDS after vaginal SIV challenge in rhesus macaques immunized with virulence attenuated SHIV 89.6," Journal of Internal Medicine, vol. 265, no. 1, pp. 67-77, 2009.

[13] J. M. Greene, J. J. Lhost, B. J. Burwitz et al., "Extralymphoid $\mathrm{CD}^{+} \mathrm{T}$ cells resident in tissue from simian immunodeficiency virus SIVmac239 $\triangle$ nef-vaccinated macaques suppress SIVmac239 replication ex vivo," The Journal of Virology, vol. 84, no. 7, pp. 3362-3372, 2010. 
[14] M. J. McElrath, S. C. De Rosa, Z. Moodie et al., "HIV-1 vaccine-induced immunity in the test-of-concept Step Study: a case-cohort analysis," The Lancet, vol. 372, no. 9653, pp. 1894 1905, 2008.

[15] T. Demberg and M. Robert-Guroff, "Mucosal immunity and protection against HIV/SIV infection: strategies and challenges for vaccine design," International Reviews of Immunology, vol. 28, no. 1-2, pp. 20-48, 2009.

[16] J. R. Almeida, D. Sauce, D. A. Price et al., "Antigen sensitivity is a major determinant of $\mathrm{CD}^{+} \mathrm{T}$-cell polyfunctionality and HIV-suppressive activity," Blood, vol. 113, no. 25, pp. 63516360, 2009.

[17] V. Appay, R. A. W. Van Lier, F. Sallusto, and M. Roederer, "Phenotype and function of human T lymphocyte subsets: consensus and issues," Cytometry Part A, vol. 73, no. 11, pp. 975-983, 2008.

[18] M. C. Iglesias, J. R. Almeida, S. Fastenackels et al., "Escape from highly effective public $\mathrm{CD}^{+}$T-cell clonotypes by HIV," Blood, vol. 118, no. 8, pp. 2138-2149, 2011.

[19] Q. Li, P. J. Skinner, S. J. Ha et al., "Visualizing antigen-specific and infected cells in situ predicts outcomes in early viral infection," Science, vol. 323, no. 5922, pp. 1726-1729, 2009.

[20] H. Streeck, Z. L. Brumme, M. Anastario et al., "Antigen load and viral sequence diversification determine the functional profile of HIV-1-specific CD8 ${ }^{+}$T cells," PLoS Medicine, vol. 5, no. 5, article e100, 2008.

[21] S. G. Hansen, J. C. Ford, M. S. Lewis et al., "Profound early control of highly pathogenic SIV by an effector memory T-cell vaccine," Nature, vol. 473, no. 7348, pp. 523-527, 2011.

[22] S. A. Migueles, C. M. Osborne, C. Royce et al., "Lytic granule loading of $\mathrm{CD}^{+} \mathrm{T}$ cells is required for HIV-infected cell elimination associated with immune control," Immunity, vol. 29, no. 6, pp. 1009-1021, 2008.

[23] B. Poonia, C. D. Pauza, and M. S. Salvato, "Role of the Fas/FasL pathway in HIV or SIV disease," Retrovirology, vol. 6, article 91, 2009.

[24] M. Genescà, P. J. Skinner, J. H. Jung et al., "With minimal systemic T-cell expansion, $\mathrm{CD}^{+} \mathrm{T}$ cells mediate protection of rhesus macaques immunized with attenuated simian-human immunodeficiency virus SHIV89.6 from vaginal challenge with simian immunodeficiency virus," The Journal of Virology, vol. 82, no. 22, pp. 11181-11196, 2008.

[25] E. Rollman, M. Z. Smith, A. G. Brooks et al., "Killing kinetics of simian immunodeficiency virus-specific $\mathrm{CD}^{+} \mathrm{T}$ cells: implications for HIV vaccine strategies," Journal of Immunology, vol. 179, no. 7, pp. 4571-4579, 2007.

[26] B. L. Shacklett, J. W. Critchfield, A. L. Ferre, and T. L. Hayes, "Mucosal T-cell responses to HIV: responding at the front lines," Journal of Internal Medicine, vol. 265, no. 1, pp. 58-66, 2009.

[27] P. Wolint, M. R. Betts, R. A. Koup, and A. Oxenius, "Immediate cytotoxicity but not degranulation distinguishes effector and memory subsets of $\mathrm{CD}^{+} \mathrm{T}$ cells," Journal of Experimental Medicine, vol. 199, no. 7, pp. 925-936, 2004.

[28] M. R. Betts and R. A. Koup, "Detection of T-cell degranulation: CD107a and b," Methods in Cell Biology, vol. 2004, no. 75, pp. 497-512, 2004.

[29] M. R. Betts, M. C. Nason, S. M. West et al., "HIV nonprogressors preferentially maintain highly functional HIV-specific CD8 ${ }^{+}$T cells," Blood, vol. 107, no. 12, pp. 4781-4789, 2006.

[30] M. Genescà, T. Rourke, J. Li et al., "Live attenuated lentivirus infection elicits polyfunctional simian immunodeficiency virus Gag-specific $\mathrm{CD}^{+} \mathrm{T}$ cells with reduced apoptotic susceptibility in rhesus macaques that control virus replication after challenge with pathogenic SIVmac239," Journal of Immunology, vol. 179, no. 7, pp. 4732-4740, 2007.

[31] M. R. Betts and A. Harari, "Phenotype and function of protective T cell immune responses in HIV," Current Opinion in HIV and AIDS, vol. 3, no. 3, pp. 349-355, 2008.

[32] D. A. Price, T. E. Asher, N. A. Wilson et al., "Public clonotype usage identifies protective gag-specific $\mathrm{CD}^{+} \mathrm{t}$ cell responses in SIV infection," Journal of Experimental Medicine, vol. 206, no. 4, pp. 923-936, 2009.

[33] C. L. Althaus and R. J. De Boer, "Dynamics of immune escape during HIV/SIV infection,” PLoS Computational Biology, vol. 4, no. 7, Article ID e1000103, 2008.

[34] M. R. Betts, D. A. Price, J. M. Brenchley et al., "The functional profile of primary human antiviral $\mathrm{CD}^{+} \mathrm{T}$ cell effector activity is dictated by cognate peptide concentration," Journal of Immunology, vol. 172, no. 10, pp. 6407-6417, 2004.

[35] I. M. Belyakov, D. Isakov, Q. Zhu, A. Dzutsev, and J. A. Berzofsky, "A novel functional CTL avidity/activity compartmentalization to the site of mucosal immunization contributes to protection of macaques against simian/human immunodeficiency viral depletion of mucosal $\mathrm{CD}^{+} \mathrm{T}$ cells," Journal of Immunology, vol. 178, no. 11, pp. 7211-7221, 2007.

[36] C. T. Berger, N. Frahm, D. A. Price et al., "High-functionalavidity cytotoxic T lymphocyte responses to HLA-B-restricted Gag-derived epitopes associated with relative HIV control," Journal of Virology, vol. 85, no. 18, pp. 9334-9345, 2011.

[37] H. T. Jin, R. Ahmed, and T. Okazaki, "Role of PD-1 in regulating T-cell immunity," Current Topics in Microbiology and Immunology, vol. 350, pp. 17-37, 2011.

[38] S. D. Blackburn, H. Shin, W. N. Haining et al., "Coregulation of $\mathrm{CD}^{+} \mathrm{T}$ cell exhaustion by multiple inhibitory receptors during chronic viral infection," Nature Immunology, vol. 10, no. 1, pp. 29-37, 2009.

[39] M. Quigley, F. Pereyra, B. Nilsson et al., "Transcriptional analysis of HIV-specific $\mathrm{CD}^{+} \mathrm{T}$ cells shows that PD- 1 inhibits T cell function by upregulating BATF," Nature Medicine, vol. 16, no. 10, pp. 1147-1151, 2010.

[40] V. Velu, K. Titanji, B. Zhu et al., "Enhancing SIV-specific immunity in vivo by PD-1 blockade," Nature, vol. 458, no. 7235, pp. 206-210, 2009.

[41] S. M. Henson, O. Franzese, R. Macaulay et al., "KLRG1 signaling induces defective Akt (ser473) phosphorylation and proliferative dysfunction of highly differentiated $\mathrm{CD}^{+} \mathrm{T}$ cells," Blood, vol. 113, no. 26, pp. 6619-6628, 2009.

[42] S. Koch, A. Larbi, E. Derhovanessian, D. Özcelik, E. Naumova, and G. Pawelec, "Multiparameter flow cytometric analysis of CD4 and CD8 T cell subsets in young and old people," Immunity and Ageing, vol. 5, article 6, 2008.

[43] J. M. Brenchley, N. J. Karandikar, M. R. Betts et al., "Expression of CD57 defines replicative senescence and antigen-induced apoptotic death of $\mathrm{CD}^{+}$T cells," Blood, vol. 101, no. 7, pp. 2711-2720, 2003.

[44] P. K. Chattopadhyay, M. R. Betts, D. A. Price et al., "The cytolytic enzymes granyzme A, granzyme B, and perforin: expression patterns, cell distribution, and their relationship to cell maturity and bright CD57 expression," Journal of Leukocyte Biology, vol. 85, no. 1, pp. 88-97, 2009.

[45] Y. Le Priol, D. Puthier, C. Lécureuil et al., "High cytotoxic and specific migratory potencies of senescent $\mathrm{CD} 8^{+} \mathrm{CD} 57^{+}$ cells in HIV-infected and uninfected individuals," Journal of Immunology, vol. 177, no. 8, pp. 5145-5154, 2006. 
[46] H. Streeck, D. S. Kwon, A. Pyo et al., "Epithelial adhesion molecules can inhibit HIV-1-specific CD8 ${ }^{+}$T-cell functions," Blood, vol. 117, no. 19, pp. 5112-5122, 2011.

[47] C. Petrovas, B. Chaon, D. R. Ambrozak et al., "Differential association of programmed death-1 and CD57 with ex vivo survival of $\mathrm{CD}^{+} \mathrm{T}$ cells in HIV infection," Journal of Immunology, vol. 183, no. 2, pp. 1120-1132, 2009.

[48] G. Breton, B. Yassine-Diab, L. Cohn et al., "SiRNA knockdown of PD-L1 and PD-L2 in monocyte-derived dendritic cells only modestly improves proliferative responses to gag by $\mathrm{CD}^{+}$ T cells from HIV-1-infected individuals," Journal of Clinical Immunology, vol. 29, no. 5, pp. 637-645, 2009.

[49] K. Newton and A. Strasser, "Cell death control in lymphocytes," Advances in Immunology, vol. 76, pp. 179-226, 2000.

[50] A. V. Gett, F. Sallusto, A. Lanzavecchia, and J. Geginat, "T cell fitness determined by signal strength," Nature Immunology, vol. 4, no. 4, pp. 355-360, 2003.

[51] J. V. Giorgi, H.-N. Ho, K. Hirji et al., "CD8 ${ }^{+}$lymphocyte activation at human immunodeficiency virus type 1 seroconversion: development of HLA-DR+ CD38- CD8 ${ }^{+}$cells is associated with subsequent stable CD4 ${ }^{+}$cell levels," Journal of Infectious Diseases, vol. 170, no. 4, pp. 775-781, 1994.

[52] J. V. Giorgi, "Phenotype and function of T cells in HIV disease," in Immunology of HIV Infection, S. Gupta, Ed., pp. 181-199, Plenum Press, New York, NY, USA, 1996.

[53] M. Genescà, J. Li, L. Fritts et al., "Depo-Provera abrogates attenuated lentivirus-induced protection in male rhesus macaques challenged intravenously with pathogenic SIVmac239," Journal of Medical Primatology, vol. 36, no. 4-5, pp. 266-275, 2007.

[54] J. D. Miller, R. G. van der Most, R. S. Akondy et al., "Human effector and memory $\mathrm{CD}^{+} \mathrm{T}$ cell responses to smallpox and yellow fever vaccines," Immunity, vol. 28, no. 5, pp. 710-722, 2008.

[55] F. Hladik and M. J. McElrath, "Setting the stage: host invasion by HIV," Nature Reviews Immunology, vol. 8, no. 6, pp. 447457, 2008.

[56] B. F. Keele, H. Li, G. H. Learn et al., "Low-dose rectal inoculation of rhesus macaques by SIVsmE660 or SIVmac251 recapitulates human mucosal infection by HIV-1," Journal of Experimental Medicine, vol. 206, no. 5, pp. 1117-1134, 2009.

[57] C. J. Miller, Q. Li, K. Abel et al., "Propagation and dissemination of infection after vaginal transmission of simian immunodeficiency virus," The Journal of Virology, vol. 79, no. 14, pp. 9217-9227, 2005.

[58] F. Sallusto, J. Geginat, and A. Lanzavecchia, "Central memory and effector memory $\mathrm{T}$ cell subsets: function, generation, and maintenance," Annual Review of Immunology, vol. 22, pp. 745$763,2004$.

[59] S. G. Hansen, C. Vieville, N. Whizin et al., "Effector memory $\mathrm{T}$ cell responses are associated with protection of rhesus monkeys from mucosal simian immunodeficiency virus challenge," Nature Medicine, vol. 15, no. 3, pp. 293-299, 2009.

[60] M. Genescà and C. J. Miller, "Use of nonhuman primate models to develop mucosal AIDS vaccines," Current HIV/AIDS Reports, vol. 7, no. 1, pp. 19-27, 2010.

[61] R. M. Zinkernagel, "On natural and artificial vaccinations," Annual Review of Immunology, vol. 21, pp. 515-546, 2003.

[62] M. Jeyanathan, J. Mu, S. McCormick et al., "Murine airway luminal antituberculosis memory CD8 $\mathrm{T}$ cells by mucosal immunization are maintained via antigen-driven in situ proliferation, independent of peripheral T cell recruitment," American Journal of Respiratory and Critical Care Medicine, vol. 181, no. 8, pp. 862-872, 2010.
[63] B. F. Haynes and R. J. Shattock, "Critical issues in mucosal immunity for HIV-1 vaccine development," Journal of Allergy and Clinical Immunology, vol. 122, no. 1, pp. 3-9, 2008.

[64] B. D. Walker and D. R. Burton, "Toward an AIDS vaccine," Science, vol. 320, no. 5877, pp. 760-764, 2008.

[65] S. Rerks-Ngarm, P. Pitisuttithum, S. Nitayaphan et al., "Vaccination with ALVAC and AIDSVAX to prevent HIV-1 infection in Thailand," The New England Journal of Medicine, vol. 361, no. 23, pp. 2209-2220, 2009.

[66] K. Abel, L. Compton, T. Rourke et al., "Simian-human immunodeficiency virus SHIV89.6-induced protection against intravaginal challenge with pathogenic SIVmac239 is independent of the route of immunization and is associated with a combination of cytotoxic T-lymphocyte and alpha interferon responses," The Journal of Virology, vol. 77, no. 5, pp. 3099-3118, 2003.

[67] R. P. Johnson and R. C. Desrosiers, "Protective immunity induced by live attenuated simian immunodeficiency virus," Current Opinion in Immunology, vol. 10, no. 4, pp. 436-443, 1998.

[68] B. L. Lohman, M. B. McChesney, C. J. Miller et al., "A partially attenuated simian immunodeficiency virus induces host immunity that correlates with resistance to pathogenic virus challenge," The Journal of Virology, vol. 68, no. 11, pp. 7021-7029, 1994.

[69] T. H. Mogensen, J. Melchjorsen, C. S. Larsen, and S. R. Paludan, "Innate immune recognition and activation during HIV infection," Retrovirology, vol. 7, article 54, 2010.

[70] I. Pandrea, T. Gaufin, J. M. Brenchley et al., "Cutting edge: experimentally induced immune activation in natural hosts of simian immunodeficiency virus induces significant increases in viral replication and $\mathrm{CD} 4^{+} \mathrm{T}$ cell depletion," Journal of Immunology, vol. 181, no. 10, pp. 6687-6691, 2008.

[71] R. E. Owen, J. W. Heitman, D. F. Hirschkorn et al., "HIV+ elite controllers have low HIV-specific T-cell activation yet maintain strong, polyfunctional T-cell responses," AIDS, vol. 24, no. 8, pp. 1095-1105, 2010.

[72] M. Stone, Z. M. Ma, M. Genescà et al., "Limited dissemination of pathogenic SIV after vaginal challenge of rhesus monkeys immunized with a live, attenuated lentivirus," Virology, vol. 392, no. 2, pp. 260-270, 2009.

[73] M. Genescà, P. J. Skinner, K. M. Bost, D. Lu et al., "Protective attenuated lentivirus immunization induces SIV-specific T cells in the genital tract of rhesus monkeys," Mucosal Immunology, vol. 1, no. 3, pp. 219-228, 2008.

[74] A. L. Ferre, P. W. Hunt, D. H. McConnell et al., "HIV controllers with HLA-DRB1* 13 and HLA-DQB1* 06 alleles have strong, polyfunctional mucosal CD4 ${ }^{+}$T-cell responses," The Journal of Virology, vol. 84, no. 21, pp. 11020-11029, 2010.

[75] S. A. Kalams and B. D. Walker, "The critical need for CD4 help in maintaining effective cytotoxic T lymphocyte responses," Journal of Experimental Medicine, vol. 188, no. 12, pp. 21992204, 1998.

[76] J. Estaquier and J. J. Zaunders, "Cytokines and the pathogenesis of HIV infection," European Cytokine Network, vol. 21, no. 3, pp. 195-196, 2010.

[77] A. Viola, B. Molon, and R. L. Contento, "Chemokines: coded messages for T-cell missions," Frontiers in Bioscience, vol. 13, pp. 6341-6353, 2008.

[78] J. T. Harty and V. P. Badovinac, "Shaping and reshaping CD8 ${ }^{+}$ T-cell memory," Nature Reviews Immunology, vol. 8, no. 2, pp. 107-119, 2008.

[79] B. Jacquelin, V. Mayau, B. Targat et al., "Nonpathogenic SIV infection of African green monkeys induces a strong but 
rapidly controlled type I IFN response," The Journal of Clinical Investigation, vol. 119, no. 12, pp. 3544-3555, 2009.

[80] G. Zelinskyy, K. K. Dietze, Y. P. Hüsecken et al., "The regulatory T-cell response during acute retroviral infection is locally defined and controls the magnitude and duration of the virus-specific cytotoxic T-cell response," Blood, vol. 114, no. 15, pp. 3199-3207, 2009.

[81] C. M. Card, P. J. McLaren, C. Wachihi, J. Kimani, F. A. Plummer, and K. R. Fowke, "Decreased immune activation in resistance to HIV-1 infection is associated with an elevated frequency of $\mathrm{CD} 8^{+} \mathrm{CD} 25^{+} \mathrm{FOXP} 3^{+}$regulatory T rells," Journal of Infectious Diseases, vol. 199, no. 9, pp. 1318-1322, 2009.

[82] S. N. Gordon, N. R. Klatt, S. E. Bosinger et al., "Severe depletion of mucosal $\mathrm{CD}^{+} \mathrm{T}$ cells in AIDS-free simian immunodeficiency virus-infected sooty mangabeys," Journal of Immunology, vol. 179, no. 5, pp. 3026-3034, 2007.

[83] I. Pandrea, C. Apetrei, J. Dufour et al., "Simian immunodeficiency virus SIVagm.sab infection of Caribbean African green monkeys: a new model for the study of SIV pathogenesis in natural hosts," The Journal of Virology, vol. 80, no. 10, pp. 4858-4867, 2006.

[84] I. V. Pandrea, R. Gautam, R. M. Ribeiro et al., "Acute loss of intestinal $\mathrm{CD}^{+} \mathrm{T}$ cells is not predictive of simian immunodeficiency virus virulence," Journal of Immunology, vol. 179, no. 5, pp. 3035-3046, 2007.

[85] K. A. Kraynyak, M. A. Kutzler, N. J. Cisper et al., "Systemic immunization with CCL27/CTACK modulates immune responses at mucosal sites in mice and macaques," Vaccine, vol. 28, no. 8, pp. 1942-1951, 2010. 


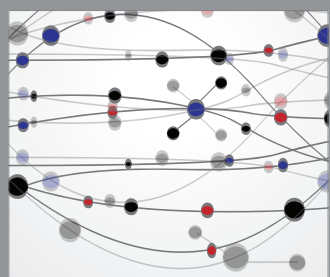

The Scientific World Journal
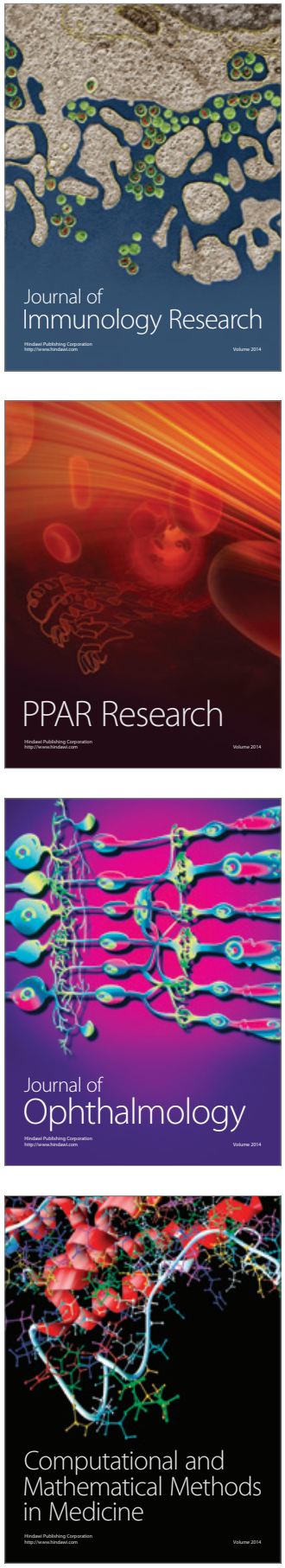

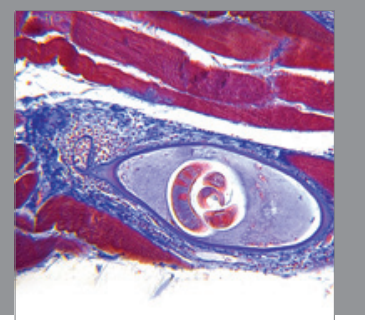

Gastroenterology

Research and Practice
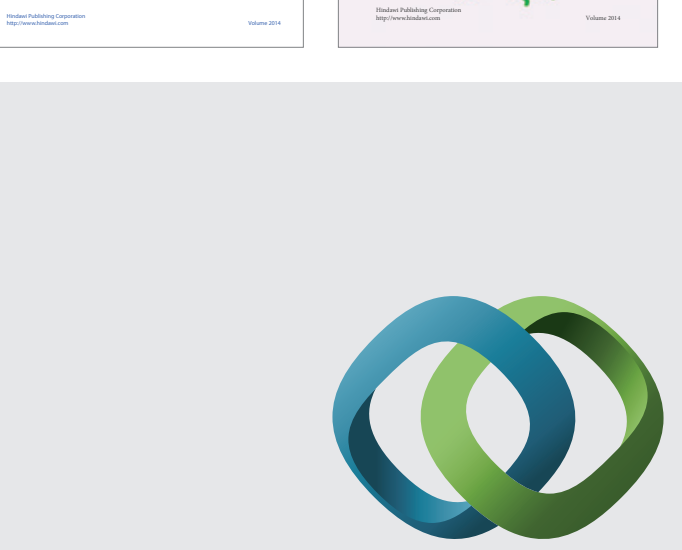

\section{Hindawi}

Submit your manuscripts at

http://www.hindawi.com
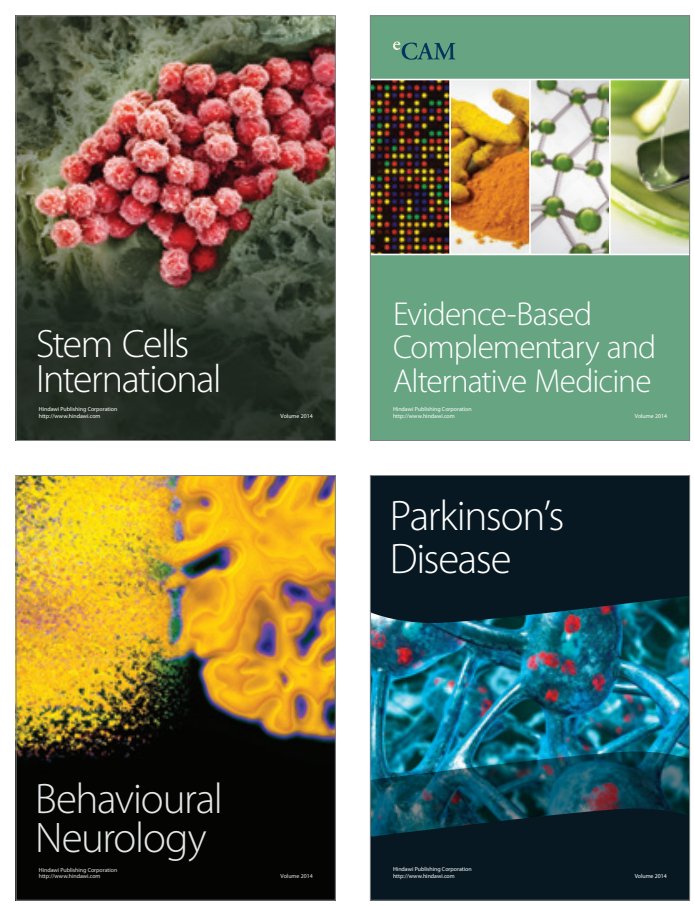

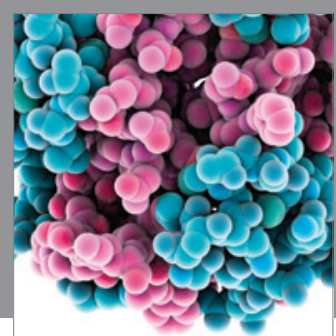

Journal of
Diabetes Research

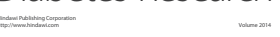

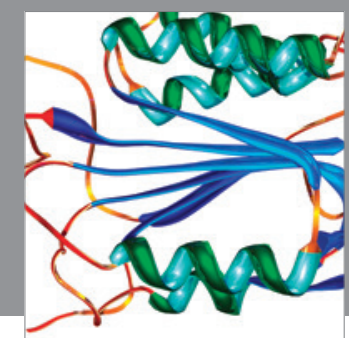

Disease Markers
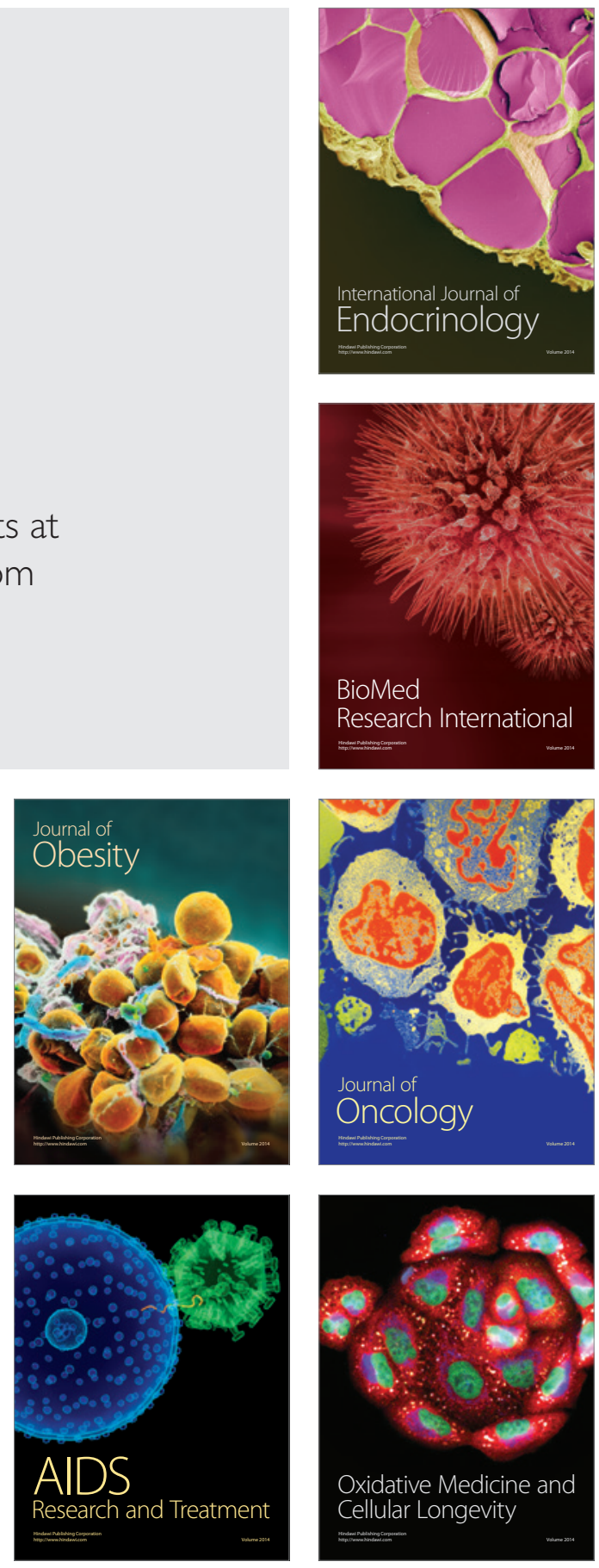